This is a pre-print of an article published in Behavior and Social Issues. The final authenticated version is available online at: https://doi.org/10.1007/s42822-021-00057-z

\title{
Perceptions of Behavior Analysis in La Francophonie: Accuracy and Tone of Posts in an Internet Forum on Autism
}

\author{
Stéphanie Turgeon ${ }^{1}$ and Marc J. Lanovaz ${ }^{1,2}$ \\ ${ }^{1}$ École de psychoéducation, Université de Montréal \\ ${ }^{2}$ Centre de recherche de l'Institut universitaire en santé mentale de Montréal
}

\section{Author Note}

This paper was written in partial fulfillment of the requirements of the Ph.D. degree in Psychoeducation at the Université de Montréal by the first author. This study was supported in part by a scholarship from the Social Sciences and Humanities Research Council to the first author and by a salary award from the Fonds de recherche du Québec - Santé (\#269462) to the second author. The authors would like to acknowledge Noémie Hogan for her assistance with the interrater agreement.

Correspondence concerning this article should be addressed to Marc J. Lanovaz, École de psychoéducation, Université de Montréal, C.P. 6128, succursale Centre-Ville, Montreal, QC, Canada, H3C 3J7. Email: marc.lanovaz@umontreal.ca, Phone: 1 514-343-6111 \#81774 


\begin{abstract}
Applied behavior analysis ( $\mathrm{ABA}$ ) remains highly contested and under-utilized in many countries for the treatment of individuals with autism. One country where ABA remains particularly difficult to access is France. One potential problem is that parents often rely on online resources such as social media to identify interventions for their child. These sources of information may not accurately portray ABA or even openly disapprove of the approach. To examine this issue, we used data mining methodology to extract, categorize, and analyze 897 messages on ABA published in a popular French internet forum based on their type, tone, and accuracy. Although messages were generally accurate and approving of ABA, our results showed that one in three messages fully or partially disapproved of the approach and one in four messages contained some inaccurate information. Our analyses also indicated that parents were more likely to approve of ABA than individuals with an autism spectrum disorder. Finally, we found that the number of approving messages published in the internet forum decreased with time, especially over the last five years. Together, these results support the relevance of developing system-level approaches to dispel misconceptions about ABA in languages other than English.
\end{abstract}

Keywords: autism, behavior analysis, data mining, French, internet forum, perception. 


\section{Perceptions of Behavior Analysis in La Francophonie: Accuracy and Tone of Posts in an Internet Forum on Autism}

Over 70 years ago, Ayllon and Micheal (1959) as well as Williams (1959) published the first studies using the principles of behavior analysis to solve problems of applied significance. Since then, research and clinical practice within the field of applied behavior analysis (ABA) have flourished and led to the creation of the Journal of Applied Behavior Analysis and of the Behavior Analyst Certification Board®. Initially practiced predominantly in the United States of America, ABA has migrated to countries across all five continents (Ardila, 2006; Johnston et al., 2017). Researchers have studied the effectiveness of ABA as a treatment for a variety of populations (Fisher et al., 2013). Notably, the body of research on behavior analytic interventions for persons with an autism spectrum disorder (ASD) has proliferated over the past decades (e.g., Leaf et al., 2016; Roth et al., 2014; Wong et al., 2015). With the consistent increase in prevalence of ASD (Frombonne, 2018), clinical practice of ABA has also shifted. A majority of certified clinicians now work with individuals on the spectrum (Association of Professional Behavior Analysts, 2009; Deochand \& Fuqua, 2016).

Behavior analytic interventions are functional interventions based on learning theory that aim to modify the antecedents and consequences associated with a behavior as well as to teach alternatives (Leaf et al., 2008). Researchers consider interventions based on behavior analytic principles as well established for the treatment of autism (National Autism Center, 2015). Many evidence-based treatments for ASD grounded in ABA have led to positive effects on a variety of communication, social, behavior, academic, adaptive, and cognitive outcomes (Hyman et al., 2020; Roth et al., 2014; Wong et al., 2015). In fact, behavior analytic interventions have the most 
empirical evidence for decreasing challenging behaviors and teaching adaptive behaviors to children with ASD (Roth, et al., 2014; Wong et al., 2015).

Even though interventions based on behavior analytic principles for individuals with ASD are established as evidenced-based, their use remains contested and under-utilized in many countries (Freedman, 2016; Krapfl, 2016). One country where ABA remains particularly contested and difficult to access is France (Amoureux, 2017). It is possible that, to some extent, the absence of recognition of the effectiveness of ABA for the treatment of ASD by France's higher health authorities until 2012 (Haute Autorité de Santé and Agence Nationale de l'Évaluation et de la Qualité des Établissements et Services Sociaux et Médico-Sociaux, 2012) resulted in the population's limited use of behavior analytic interventions. Researchers have also suggested that the vocabulary used by our science (e.g., "normalize", "control", "operant") and a limited understanding of the field of behavior analysis are underlying elements resulting in misconceptions regarding ethical use and effectiveness of these interventions (Freedman, 2017; Keenan, 2015; Krapfl, 2016).

Parents play a major role in selecting interventions and treatments for their child (Green, 2007; McPhilemy \& Dillenburger, 2013). When identifying potential treatments, parents are faced with an overwhelming amount of information (Miller et al., 2012; National Autism Center, 2015). For example, hundreds of different interventions exist for children with ASD with varying proof of effectiveness (Goin-Kotchel et al., 2007; Miller et al., 2012; National Autism Center, 2015). These treatments can range from drug treatments and diet therapies to behavioral, educational, and alternative interventions. Parents can seek information on potential treatments from a diversity of sources such as health professionals, books, newspapers, other parents, and the internet (Miller et al., 2012). Advances in technology and increased accessibility to the 
internet make the latter an important source of knowledge acquisition for parents of children with ASD (e.g., Grant et al., 2016; Hall et al., 2016; Pham et al., 2019). While Gibson et al. (2017) found that parents prefer obtaining information relating to ASD from local resources (e.g., pediatricians, teachers, and local organizations), results from other studies have suggested that the internet is increasingly used as parents' primary source of information (Grant et al., 2016; Hall et al., 2016). A recent study by Shepherd et al. (2020) found that nearly $45 \%$ of the parents in their sample reported using social media for caregiving-related support. In another example, Clifford and Minnes (2013) noted that $31 \%$ of the parents of children with ASD in their study were actively using online support groups.

Social media platforms, such as Facebook, Twitter, blogs, and internet forums, are online resources that are particularly interesting as they not only give the parent access to large amounts of information, but also allow parents to get emotional support, interact with others and get answers to specific questions such as treatment recommendations (Saha \& Agarwal, 2016; Sherpherd et al., 2020). Although social media can be a helpful resource for parents of children with ASD, researchers have found that they contain an overabundance of information that is often unreliable and contradictory (Moorhead et al., 2013). Given that parents have reported that empirical evidence does not seem to influence treatment selection (Green et al., 2006) and that opinions or shared experiences of others are considered evidence of the effectiveness of treatments (Grant et al., 2016), relying on information found on social media can potentially result in parents selecting ineffective, or even dangerous, treatments for their child (Moorhead et al., 2013).

Acceptance of ABA is not unanimous in France, but no research has empirically measured the quantity or the quality of information from social media on ABA and autism. In 
light of the results underlining that parents often use information from social media when identifying and selecting treatments for their child, researchers need to understand what Frenchspeaking parents are exposed to when using social media to obtain information on interventions based on behavior analytic principles. To address this issue, we examined messages about ABA in a French internet forum on ASD. The specific objectives of our study were to: 1) measure the perception of ABA by quantifying the information on accuracy and tone, 2) assess whether messages with varying tones differed in accuracy, 3) evaluate whether messages with varying tones differed across the type of user (parent or person with autism), and 4) examine whether the tone of more recent messages differed from older ones.

\section{Method}

\section{Data Source}

The first author identified a popular French internet forum for people with autism and their families using the Google search engine. This internet forum had at least 500 messages pertaining to ABA and is one of the most popular autism boards published in French, which is why we selected it for our analysis. The website divided the forum into multiple subforums with specific themes. We focused our analyses on subforums that had themes involving autism in general, parents of children with autism, and treatment.

\section{Data Extraction}

Our data extraction process involved four steps. First, we hired a web data extraction service team to extract all messages as well as identification (message URL, message ID, and thread ID) and descriptive (subforum label, thread title, authors username, authors message ID, timestamp, and number of views) information for the targeted subforums. Second, a list of French keywords associated with ABA was created by the first author and approved by the 
second author (see Table 1 for the list of keywords). For the third step, we used Python as a keyword processing tool to identify messages relating to ABA that contained the keywords presented in Table 1. Finally, the first author manually searched each message to remove those with a confounded use of one of the keywords (e.g., GABA, tabac [tobacco], abandonner [abandon], or thérapie comportementale cognitive [cognitive behavior therapy]). Our final sample contained 897 messages.

\section{Data Classification}

Following the data extraction process, the first author manually coded each message in relation to three categories of characteristics: type of message, tone, and accuracy. While the type of message referred to the message as a whole, the remaining categories were coded based on the sections of the message pertaining to ABA (see Table 2 for the definition of the characteristics for each category). To assess interrater reliability, an independent rater coded $25 \%$ $(n=224)$ of the messages, which were selected at random. Interrater reliability was quantified using the kappa coefficient to control for high accuracy scores resulting from chance when coding a binary variable (i.e., 50\%; McHugh, 2012). Prior to calculating the kappa values, we transformed each characteristic to a binary variable. Kappa coefficients varied from .48 to .80 $($ mean $=.67)$. With the exception of one value, all kappa values remained above .60, indicating that our interrater agreement for coding was moderate to strong.

The third objective involved identifying user status (i.e., parent or person with ASD) so that we could conduct a more fine-grained analysis of tone. To address this issue, the first author also manually searched all user signatures at the end of each message in the internet forum. Within this signature, users often stated their relationship to ASD (e.g., father of two children with an ASD or diagnosed with Asperger's syndrome in 2011). When the signature did not 
clearly allow the identification of a user status, messages written by the user were hand searched to find this information. The dataset contained 193 different users in total: 85 users reported being a parent, 57 users reported having a diagnosis of ASD, 38 users reported neither being a parents or a person with ASD (e.g., pre-diagnostic, social communication disorder, students, practitioners), 9 users reported having both ASD and a child with ASD, and 4 users has unidentifiable statuses. We excluded the latter three categories from our analyses involving user status because our objective was to compare the perception of parents with the perception of individuals with ASD.

\section{Data Analysis}

First, we used descriptive statistics to quantify the prevalence for each category of the three main characteristics. Second, contingency tables were drawn to obtain the frequency distributions and conditional probabilities for all pairs of characteristics of tone (i.e., approving, disapproving, mixed, or neutral) and accuracy (accurate, inaccurate, mixed, or accuracy does not apply). Third, a chi-square analysis was used to test whether messages differed significantly on accuracy (i.e., accurate and inaccurate) given tone (i.e., approving and disapproving). Fourth, messages of parents were compared to messages of individuals with ASD using a chi-square test to measure whether they differed by opposing tones (i.e., approving vs disapproving). Given that some users wrote more than one message and to meet the assumption of independence of observations, we ran our chi-square using the rounded integer mean of tone (i.e., $0=$ disapproving or $1=$ approving) for each user. Users $(n=8)$ with a mean of 0.5 were excluded from the analysis since the number of approving and disapproving messages published was equal; thus, the user could not be classified in one of the mutually exclusive categories. Furthermore, we also excluded parents and individuals with ASD who did not publish any 
messages with an approving or disapproving tone from this analysis. The final sample for our comparison of tone given user status contained the average rounded tone for 62 parents and 43 individuals with ASD. Finally, we ran a binary logistic regression to examine if and how time predicted the prevalence of messages with opposing tones. All statistical analyses were conducted using the R software version 4.0.3. The anonymized data and code are freely available at: https://osf.io/wceh3/.

\section{Results}

\section{Sample Description}

Our sample consisted of 897 messages from 193 different users published between 2005 and 2020. The user sought support or information in $68(8 \%)$ messages while information or support was offered in 110 (12\%) messages. Furthermore, the user provided general information in $321(36 \%)$ messages or commented on another message in $398(44 \%)$ instances. Figure 1 presents the frequency distributions for the number of words per message, the number of messages published per user, and the number of views per discussion thread following the removal of outliers (i.e., top 5\%). Table 3 also presents descriptive statistics for frequency of publication by users and message length (i.e., number of words). Base on these results, the average user posted one or two messages that contained less than 500 words and garnered more than 1,000 views.

\section{Perceptions of ABA}

To examine perceptions of ABA, we first assessed the frequency distribution of messages with information on $\mathrm{ABA}$ for all four characteristics of tone (i.e., approving, disapproving, mixed, or neutral). More than one third of messages $(n=349 ; 39 \%)$ discussed ABA in an approving manner. On the other hand, nearly one in five $(n=178 ; 20 \%)$ messages 
disapprovingly referred to ABA. Additionally, 113 (13\%) messages contained both approving and disapproving comments on ABA. Finally, 257 (29\%) messages used a non-polarized tone (i.e., neutral).

We also qualified the accuracy of the information on ABA (i.e., accurate, inaccurate, mixed, accuracy not applicable). In all, 268 (30\%) messages had information on ABA that was considered accurate and $158(18 \%)$ messages contained inaccurate information on ABA. Moreover, 43 (5\%) messages presented a mixed accuracy (i.e., containing accurate and inaccurate information). Finally, we classified 428 (48\%) messages as not applicable (i.e., reporting anecdotal information $[n=88]$ or without judgment $[n=340])$.

\section{Accuracy Given Tone}

Table 4 presents the frequency distribution and the conditional probability of accuracy given message tone. The results show that messages with an approving tone were most likely of being accurate $(n=172 ; 49 \%)$ whereas messages with a disapproving tone had the highest probability of being inaccurate $(n=110 ; 62 \%)$. To measure whether messages significantly differed based on accuracy and tone, we ran a chi-square analysis using polarized characteristics (i.e., accurate, inaccurate, approving, and disapproving). The results suggest that there was a significant association between message accuracy and tone, $\chi^{2}(1)=201.31, p<0.01$.

Specifically, our result confirms our prior observation that approving messages were more likely to be accurate. Conversely, disapproving messages were dominantly inaccurate.

\section{Tone Given User Status}

Table 5 presents the frequency distribution of polarized tone given user status.

Conditional probabilities suggest that parents were more likely to write messages approving of ABA than individuals on the spectrum. Specifically, we observed that $84 \%(n=52)$ of parents 
wrote messages with an approving tone whereas only $16 \%(n=10)$ of parents wrote messages with a disapproving tone. Results for users with ASD also suggest that they published more approving than disapproving messages. However, the contrast for users with ASD was not as important as the one observed for parents with 24 (56\%) individuals publishing more approving messages versus 19 (44\%) individuals publishing more disapproving messages. Our chi-square analysis revealed that messages significantly differ across tones and type of user $\chi^{2}(1)=8.64, p$ $<0.01$.

\section{Evaluating Tone as a Result of Time}

Figure 2 shows that the number of approving messages was mostly homogenous from 2006 to 2014, then decreased from 2015 to 2020. On the other hand, the number of disapproving messages remains generally stable. Interestingly, the number of approving messages per year was consistently superior to the number of disapproving messages, except for 2018. The result of the logistic regression suggests that time was a significant predictor of whether a message was approving or disapproving, $\mathrm{Wald}(1)=3.40, p<0.01$, with the probability of a message being approving decreasing across years.

\section{Discussion}

Although messages were generally approving of $\mathrm{ABA}$, our results suggest that the science remains contested and misunderstood in La Francophonie (i.e., French-speaking world). In fact, nearly one in four messages contained some inaccurate information on ABA. Moreover, one in three messages fully or partially disapproved of ABA. Our results also suggest that the number of approving messages on $\mathrm{ABA}$ decreased with time, indicating that the perception of ABA published in the French internet forum has deteriorated since 2005. Our analyses also indicate that messages that approved of ABA were most likely to be accurate whereas messages 
classified as disapproving of ABA were most likely to be inaccurate. Finally, our findings suggest that parents and individuals with ASD perceive ABA differently. Specifically, parents were more likely to post messages approving of ABA than individuals on the spectrum.

Parents play a major role in selecting interventions for their children. When parents are faced with challenges such as those associated with ASD (e.g., speech impairment or challenging behaviors), they often turn to social media to identify potential interventions (Grant et al., 2016; Hall et al., 2016). Grant et al. (2016) have found that parental choice of intervention is highly influenced by opinions or shared experiences of others. Our results are concerning given that the information found within one internet forum is contradicting. The level of inaccuracy of the information pertaining to ABA was especially discomforting. Notably, nearly half (43\%) of the messages with a non-neutral tone contained some inaccurate information. Beyond disapproving messages portraying ABA inaccurately (e.g., stating that there is no evidence that ABA is effective or that ABA always leads to post-traumatic stress disorder), some messages approving of ABA also presented inaccurate information (e.g., ABA heals one in five people of ASD or ABA therapy is the best resource to treat anxiety and negative thoughts). Relying on such inaccurate and confusing information may result in parents considering ABA as ineffective, which may ultimately lead them to selecting alternative, unvalidated, and potentially dangerous interventions for their child (e.g., Arnold et al., 2003; Brown et al., 2006; Heiger et al., 2008). In contrast, overgeneralizations and inexact positive effects presented in the internet forum may create false hope or lead to the use of behavior analytic interventions when not recommended.

Our results stress the importance of parents being exposed to accurate information when selecting an intervention. Practitioners and researchers must ensure that information on the effectiveness of interventions based on ABA for the treatment of ASD is disseminated and 
accessible for parents in multiple languages. Moreover, parents need to be guided on how and where to get information on ASD treatments, especially when they do not have access to professional intervention services (e.g., during the diagnosis process or when on a waiting list for intervention services). Given France's long history with psychoanalysis as the preferred treatment for ASD and recent research suggesting that ABA remains contested and difficult to access (Amoureux, 2017), efforts must also be put forward to ensure that professionals are cognizant of current evidenced-based interventions.

Nonetheless, readers should bear in mind the limitations of our study when considering the results. First, data mining social media platforms allowed us to have access to a large dataset, but the amount of descriptive information extractable remained limited. Hence, variables such as gender, age, race, and education could not be analyzed to identify potential moderators across the tone and accuracy of messages. Furthermore, the nature of our design prevents us from reaching conclusions regarding the causes of our observations. Another limitation is that our design does not allow us to generalize our finding to other social media platforms, nor to consider our results representative of perceptions and understanding of ABA in the French-speaking world. Future research should replicate this study with other social media used by parents to see how our results compare to popular platforms such as Twitter. Finally, researchers should develop strategies to effectively disseminate information on ABA in non-English speaking communities and examine their effects on the perception of behavior analysis using experimental designs. 


\section{Compliance with Ethical Standards}

Funding: This study was supported in part by a scholarship from the [removed for blind review] to the first author and by a salary award from the [removed for blind review] to the second author.

Ethical Approval: This project did not require ethical approval as the data were publicly available over the internet and the researchers did not participate in the forum.

Conflict of Interest: On behalf of all authors, the corresponding author states that there is no conflict of interest.

Availability of Code and Data: The code and data are freely available at https://osf.io/wceh3/. 


\section{References}

Amoureux, R. (2017). Beyond indifference and aversion: The critical reception and belated acceptance of behavior therapy in France. History of Psychology, 20(3), 313329. https://doi.org/10.1037/hop0000064

Ardila, R. (2006). Behavior analysis in an international context. In A.C. Brock (Ed.), Internationalizing the history of psychology (pp. 112-132). University Press.

Arnold, G. L., Hyman, S. L., Mooney, R. A., \& Kirby, R. S. (2003, 2003/08/01). Plasma amino acids profiles in children with autism: Potential risk of nutritional deficiencies. Journal of Autism and Developmental Disorders, 33(4), 449-454.

https://doi.org/10.1023/A:1025071014191

Association of Professional Behavior Analysts (2009). Retrieved November 24, 2020, from https://www.apbahome.net

Ayllon, T., \& Michael, J. (1959). The psychiatric nurse as a behavioral engineer. Journal of the Experimental Analysis of Behavior, 2(4), 323-334. https://doi.org/10.1901/jeab.1959.2323

Brown, M. J., Willis, T., Omalu, B., \& Leiker, R. (2006). Deaths resulting from hypocalcemia after administration of Edetate Disodium: 2003-2005. Pediatrics, 118, e534-e536. https://doi.org/10.1542/peds.2006-0858

Clifford, T., \& Minnes, P. (2013). Logging on: Evaluating an online support group for parents of children with autism spectrum disorders. Journal of Autism and Developmental Disorders, 43(7), 1662-1675. https://doi.org/10.1007/s10803-012-1714-6 
Deochand, N., \& Fuqua, R. W. (2016). BACB certification trends: State of the States (1999 to 2014). Behavior Analysis in Practice, 9(3), 243-252. https://doi.org/10.1007/s40617-0160118-z

Fisher, W. W., Piazza, C. C., \& Roane, H. S. (2013). Handbook of applied behavior analysis. Guilford Press.

Freedman, D. H. (2016). Improving public perception of behavior analysis. The Behavior Analyst, 39(1), 89-95. https://doi.org/10.1007/s40614-015-0045-2

Fombonne, E. (2018). Editorial: The rising prevalence of autism. Journal of Child Psychology and Psychiatry, 59(7), 717-720. https://doi.org/https://doi.org/10.1111/jcpp.12941

Gibson, A. N., Kaplan, S., \& Vardell, E. (2017). A survey of information source preferences of parents of individuals with autism spectrum disorder. Journal of Autism and Developmental Disorders, 47(7), 2189-2204. https://doi.org/10.1007/s10803-017-3127-z

Goin-Kochel, R. P., Myers, B. J., \& Mackintosh, V. H. (2007). Parental reports on the use of treatments and therapies for children with autism spectrum disorders. Research in Autism Spectrum Disorders, 1(3), 195-209. https://doi.org/10.1016/j.rasd.2006.08.006

Grant, N., Rodger, S., \& Hoffmann, T. (2016). Intervention decision-making processes and information preferences of parents of children with autism spectrum disorders. Child: Care, Health and Development, 42, 125-134. https://doi.org/10.1111/cch.12296

Green, V. A. (2007). Parental experience with treatments for autism. Journal of Developmental and Physical Disabilities, 19(2), 91-101. https://doi.org/10.1007/s10882-007-9035-y

Green, V. A., Pituch, K. A., Itchon, J., Choi, A., O’Reilly, M., \& Sigafoos, J. (2006). Internet survey of treatments used by parents of children with autism. Research in Developmental Disabilities, 27, 70-84. https://doi.org/10.1016/j.ridd.2004.12.002 
Hall, C. M., Culler, E. D., \& Frank-Webb, A. (2016). Online dissemination of resources and services for parents of children with autism spectrum disorders (ASDs): A systematic review of evidence. Review Journal of Autism and Developmental Disorders, 3(4), 273285. https://doi.org/10.1007/s40489-016-0083-z

Haute Autorité de Santé, \& Agence Nationale de l'Évaluation et de la Qualité des Établissements et Services Sociaux et Médico-Sociaux. (2012). Recommandation de bonne pratique. Autisme et autres troubles envahissants du développement: Interventions éducatives et thérapeutiques coordonnées chez l'enfant et l'adolescent [Good practice recommendation. Autism and other pervasive developmental disorders: Coordinated educational and therapeutic interventions for children and adolescents]. Retrieved November 24, 2020, from https://www.has-sante.fr/upload/docs/application/pdf/201203/argumentaire_autisme_ted_enfant_adolescent_interventions.pdf

Heiger, M. L., England, L. J., Molloy, C. A., Yu, K. F., Manning-Courtney, P., \& Mills, J. L. (2008). Reduced bone cortical thickness in boys with autism or autism spectrum disorder. Journal of Autism and Developmental Disorders, 38, 848-856. https://doi.org/10.1007/s10803-007-0453-6

Hyman S. L., Levy S. E., Myers S. M., \& American Academy of Pediatrics Council On Children With Disabilities, Section on Developmental and Behavioral Pediatrics. (2020) Identification, evaluation, and management of children with autism spectrum disorder. Pediatrics. 145(1), e20193447. https://doi.org/10.1542/peds.2019-3447

Johnston, J. M., Carr, J. E., \& Mellichamp, F. H. (2017). A history of the professional credentialing of applied behavior analysts. The Behavior Analyst, 40(2), 523-538. https://doi.org/10.1007/s40614-017-0106-9 
Keenan, M., Dillenburger, K., Röttgers, H. R., Dounavi, K., Jónsdóttir, S. L., Moderato, P., Schenk, J. J. A. M., Virués-Ortega, J., Roll-Pettersson, \& Martin, N. (2015). Autism and ABA: The gulf between North America and Europe. Review Journal of Autism and Developmental Disorders, 2(2), 167-183. https://doi.org/10.1007/s40489-014-0045-2

Krapfl, J. E. (2016). Behaviorism and society. The Behavior Analyst, 39(1), 123-129. https://doi.org/10.1007/s40614-016-0063-8

Leaf, J. B., Leaf, R., McEachin, J., Taubman, M., Ala'i-Rosales, S., Ross, R. K., Smith, T., \& Weiss, M. J. (2016). Applied behavior analysis is a science and, therefore, progressive. Journal of Autism and Developmental Disorders, 46(2), 720-731. https://doi.org/10.1007/s10803-015-2591-6

Leaf, R., Baker, D., \& McEachin, J. (2008). What is ABA? In Leaf, R., McEachin, J., \& Taubamn, M. (Eds.), Sense and nonsense in the behavioral treatment of autism: It has to be said (p.1-12). DRL Productions.

McHugh, M. L. (2012). Interrater reliability: The Kappa statistic. Biochemia Medica, 22(3), 276282.

McPhilemy, C., \& Dillenburger, K. (2013). Parents' experiences of applied behaviour analysis (ABA)-based interventions for children diagnosed with autistic spectrum disorder. British Journal of Special Education, 40(4), 154-161. https://doi.org/10.1111/1467-8578.12038

Miller, V. A., Schreck, K. A., Mulick, J. A., \& Butter, E. (2012). Factors related to parents' choices of treatments for their children with autism spectrum disorders. Research in Autism Spectrum Disorders, 6(1), 87-95. https://doi.org/10.1016/j.rasd.2011.03.008

Moorhead, S. A., Hazlett, D. E., Harrison, L., Carroll, J. K., Irwin, A., \& Hoving, C. (2013). A new dimension of health care: systematic review of the uses, benefits, and limitations of 
social media for health communication. Journal of Medical Internet Research, 15(4), e85. https://doi.org/10.2196/jmir.1933

National Autism Center. (2015). Findings and conclusions: National Standards Report, phase 2. Addressing the need for evidence-based practice guidelines for autism spectrum disorder. Retrieved December 4, 2020, from http://www.nationalautismcenter.org/resources/

Pham, A. V., Bennett, K. D., \& Zetina, H. (2019, 2019/10/01). Technology-aided interventions for individuals with autism: Implications for policy and practice. Policy Insights from the Behavioral and Brain Sciences, 6(2), 202-209. https://doi.org/10.1177/2372732219857750

Roth, M. E., Gillis, J. M., \& DiGennaro Reed, F. D. (2014). A meta-analysis of behavioral interventions for adolescents and adults with autism spectrum disorders. Journal of Behavioral Education, 23(2), 258-286. https://doi.org/10.1007/s10864-013-9189-x

Saha, A. and Agarwal, N. (2016, February). Emotional resiliency of families dealing with autism in social media. In 2016 International Joint Conference on Biomedical Engineering Systems and Technologies (pp.377-382). https://doi.org/10.5220/0005774703770382

Shepherd, D., Goedeke, S., Landon, J., \& Meads, J. (2020). The types and functions of social supports used by parents caring for a child with autism spectrum disorder. Journal of Autism and Developmental Disorders. Advance online publication. https://doi.org/10.1007/s10803-019-04359-5

Williams, C. D. (1959). The elimination of tantrum behavior by extinction procedures. The Journal of Abnormal and Social Psychology, 59(2), 269. https://doi.org/10.1037/h0046688 Wong, C., Odom, S. L., Hume, K. A., Cox, A. W., Fettig, A., Kucharczyk, S., Brock, M. E., Plavnick, J. B., Fleury, V. P., \& Schultz, T. R. (2015). Evidence-based practices for 
children, youth, and young adults with autism spectrum disorder: A comprehensive review. Journal of Autism and Developmental Disorders, 45(7), 1951-1966. https://doi.org/10.1007/s10803-014-2351-z 


\section{Table 1}

List of French and Translated Keywords used in Python Code for Message

Extraction

\begin{tabular}{ll}
\hline \multicolumn{1}{c}{ French } & \multicolumn{1}{c}{ English } \\
\hline aba & aba \\
analyse appliqu & applied analysis \\
intervention comportemental & behavioral intervention \\
interventions comportemental & behavioral interventions \\
comportementalisme & behaviorism \\
thérapie comportement & behavior* therapy \\
thérapies comportement & behavior* therapies \\
aac & aac \\
analyse comportementale appliqu & applied behavior analys* \\
comportementaliste & behaviorist \\
méthode comportement & behavior* method \\
méthodes comportement & behavior* methods \\
behavioris & behavioris \\
approche comportemental & behavior* approach \\
\hline
\end{tabular}


Table 2

Definition of Each Category for Type of Message, Tone and Accuracy

\begin{tabular}{lll}
\hline \multicolumn{1}{c}{ Type of Message } & \multicolumn{1}{c}{ Tone } & \multicolumn{1}{c}{ Accuracy } \\
\hline $\begin{array}{l}\text { 1= Question/seeking } \\
\text { information/seeking } \\
\text { support }\end{array}$ & $\begin{array}{l}\text { 1= Approving: Message } \\
\text { that promotes ABA, } \\
\text { describes its benefits, or } \\
\text { mentions positive } \\
\text { experiences with ABA. }\end{array}$ & $\begin{array}{l}\text { 1= Accurate: Message that } \\
\text { accurately describes the } \\
\text { procedures, methods, } \\
\text { interventions or effects of } \\
\text { ABA. This category excludes } \\
\text { anecdotal information. }\end{array}$ \\
& $\begin{array}{l}\text { 2= Disapproving: Message } \\
\text { that discourages the use of }\end{array}$ & $\begin{array}{l}\text { 2= Inaccurate: Message that } \\
\text { inaccurately describes the } \\
\text { procedures, methods, }\end{array}$ \\
$\begin{array}{l}\text { ABestion/responding toscribes the } \\
\text { someone seeking } \\
\text { information or support }\end{array}$ & $\begin{array}{l}\text { harmful/negative effects or } \\
\text { talks about negative } \\
\text { experiences with ABA. }\end{array}$ & $\begin{array}{l}\text { ABA. This category excludes } \\
\text { anecdotal information. }\end{array}$
\end{tabular}

3= Giving general

information or

3= Mixed: Message presenting

suggesting a resource $3=$ Mixed: Message with an (this type of message is approving and disapproving not a response to tone about ABA.

accurate and inaccurate information on ABA. This category excludes anecdotal another person's information.

message or question)

4= Commenting on another message or subject.
4= Neutral: Message that mentions ABA without using a polarized tone.
4= Non-applicable: Messages without judgment on ABA or reporting anecdotal information on ABA.

Note. Values associated for each category represent the values in the dataset available at https://osf.io/wceh3/ 
Table 3

Descriptive Statistics for our Sample

\begin{tabular}{lccccc}
\hline Characteristic & Median & Mean & SD & Min & Max \\
\hline Number of messages published by user & 2 & 4.65 & 21.96 & 1 & 303 \\
Number of words per message & 263 & 450.74 & 547.85 & 9 & 5147 \\
Number of views per discussion thread & 2,631 & 7,358 & 19,702 & 294 & 308,218 \\
\hline
\end{tabular}




\section{Table 4}

Frequency Distribution and Conditional Percentage of Accuracy Given Tone

\begin{tabular}{lcccc}
\hline & \multicolumn{4}{c}{ Tone } \\
\cline { 2 - 5 } Accuracy & Approving & Disapproving & Mixed & Neutral \\
\hline Accurate & $172(49 \%)$ & $11(6 \%)$ & $39(35 \%)$ & $46(18 \%)$ \\
Inaccurate & $17(5 \%)$ & $110(62 \%)$ & $14(12 \%)$ & $17(7 \%)$ \\
Mixed & $11(3 \%)$ & $6(3 \%)$ & $24(21 \%)$ & $2(1 \%)$ \\
Accuracy not applicable & $149(43 \%)$ & $51(29 \%)$ & $36(32 \%)$ & $192(75 \%)$ \\
\hline Total & $349(100 \%)$ & $178(100 \%)$ & $113(100 \%)$ & $257(100 \%)$ \\
\hline
\end{tabular}


Table 5

Frequency Distribution and Conditional Percentage of Polarized Tone Given User Status

\begin{tabular}{lcc}
\hline & \multicolumn{2}{c}{ User Status } \\
\cline { 2 - 3 } Tone & Parents & Individuals with ASD \\
\hline Approving & $52(84 \%)$ & $24(56 \%)$ \\
Disapproving & $10(16 \%)$ & $19(44 \%)$ \\
\hline Total & $62(100 \%)$ & $43(100 \%)$ \\
\hline
\end{tabular}

Note. ASD $=$ Autism spectrum disorder. 


\section{Figure 1}

Frequency Distribution of the Number of Words in a Message, the Number of Messages Published per User, and the Number of Views per Thread.

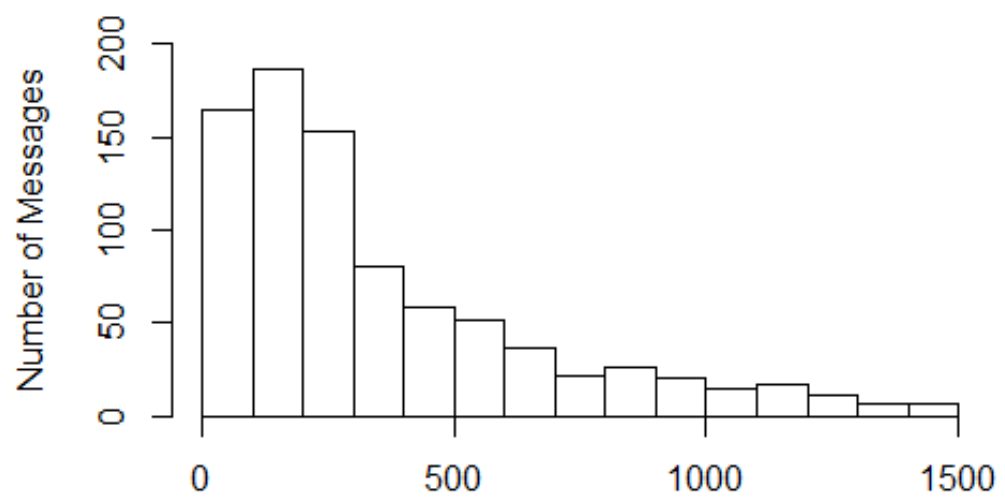

Number of Words

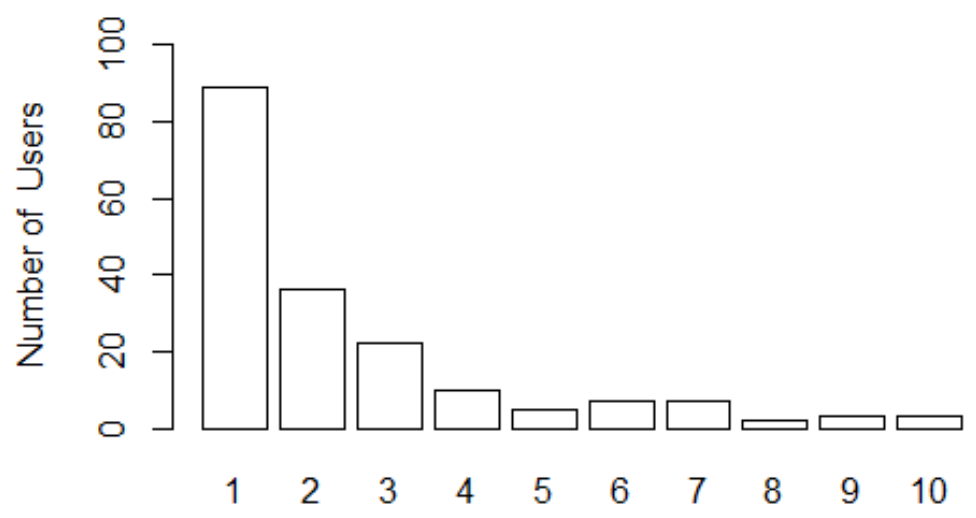

Number of Messages

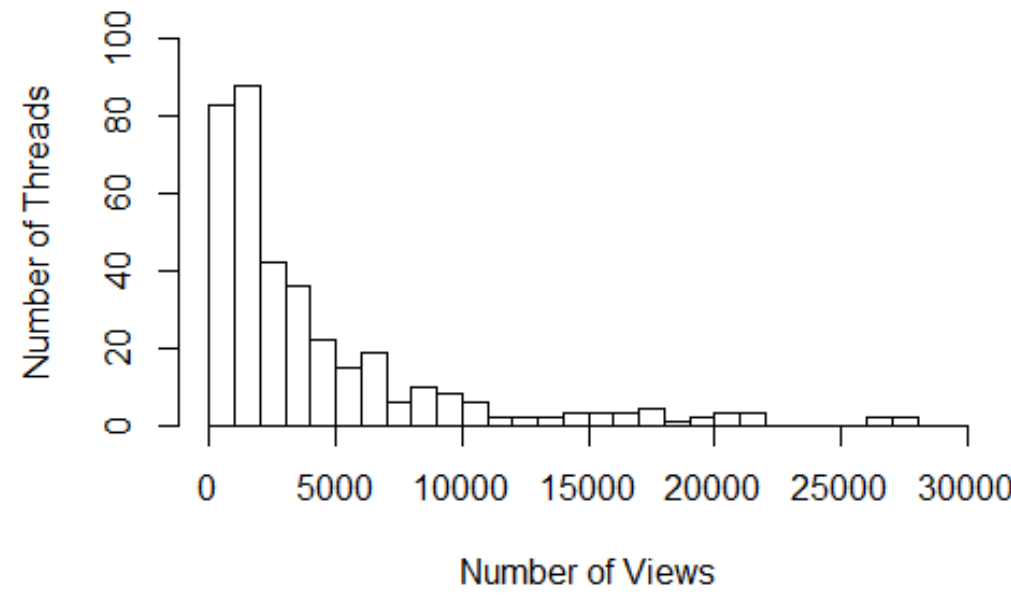

Note. The outliers (i.e., top 5\%) were removed from the graphs. 


\section{Figure 2}

Number of Messages for Each Tone Published on the Internet Forum by Year.

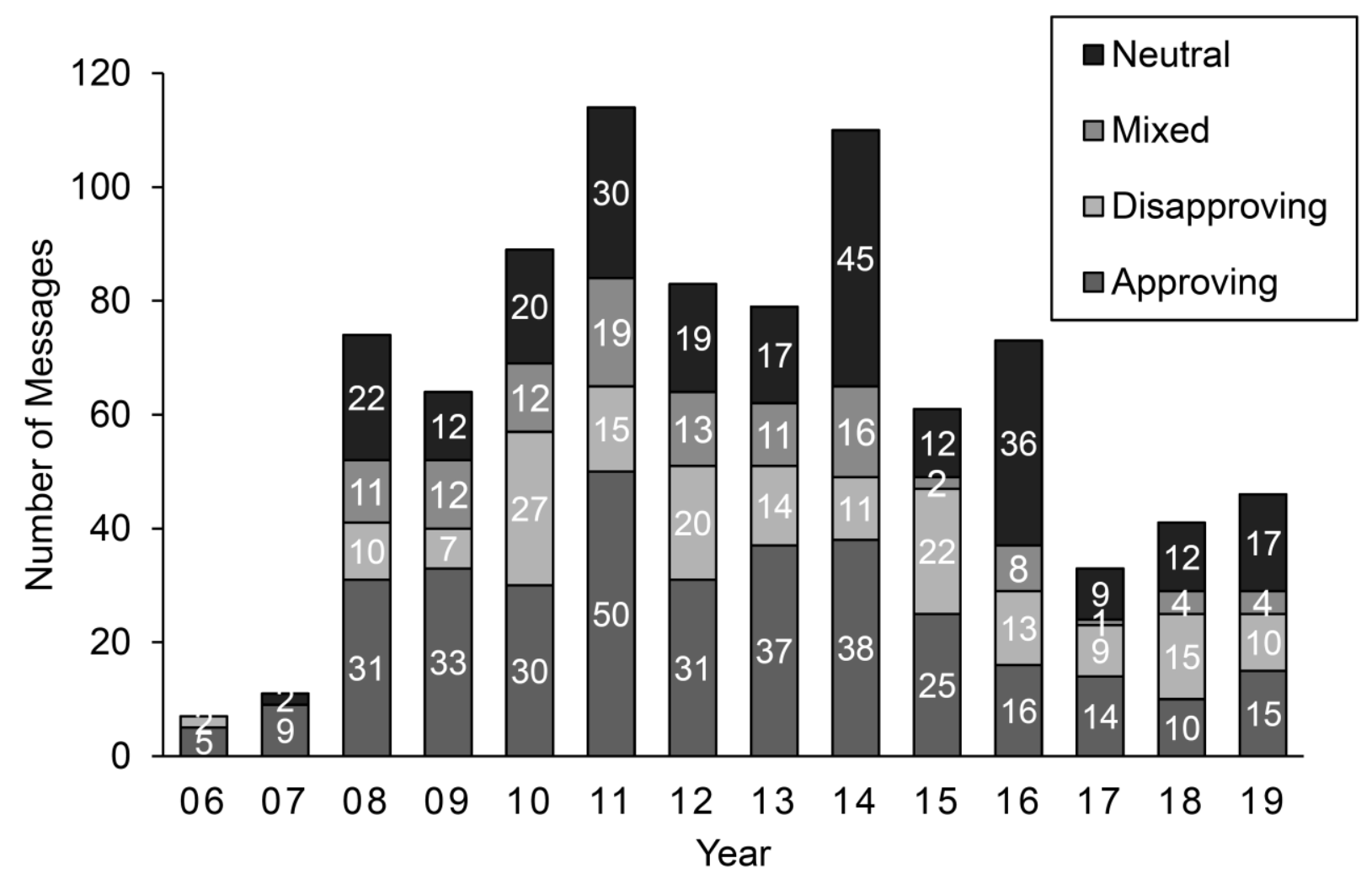

Note. We excluded messages published in 2005 and 2020 from the histogram as data were unavailable for all months of those years. 